\title{
Pact protects Canadian forests
}

\section{Huge conservation deal will benefit caribou and maybe climate.}

An unlikely coalition of logging companies and environmental groups has reached an agreement to protect more than 300,000 square kilometres of Canadian boreal forest - an area larger than the United Kingdom the biggest forest-conservation deal in history. An additional 385,000 square kilometres will fall under strict guidelines that will promote sustainable logging and protect ecologically and culturally sensitive sites.

Under the agreement, unveiled on 18 May in Toronto, Ontario, 21 members of the Forest Products Association of Canada, which represents the majority of companies in the Canadian logging industry, will set aside slightly less than half of the land for which they hold leases across seven provinces. In exchange, nine environmental groups, including Greenpeace and the Nature Conservancy, have pledged to suspend do-not-buy campaigns against the loggers' products, which range from construction lumber to toilet paper, and to actively endorse them.

"We strongly believe that every improvement in environmental quality can translate into market value for our products," says Avrim Lazar, president of the Forest Products Association.

\section{Crucial habitats}

The finer details of areas to be preserved (see 'Protection plan') will be chosen by biologists and logging companies. Their choices will have to be approved by the provincial governments and Native Canadians.

"This will allow us to protect the most intact parts of the boreal forest that are critical habitat for the caribou and other species," says Steve Kallick, director of the Pew Environment Group's International Boreal Conservation Campaign, based in Seattle, Washington, which brokered the deal it hails as "radically pragmatic".

When added to earlier commitments by Ontario, Quebec, Manitoba and the Northwest Territories as well as the federal government, this week's agreement means that 1.6 million square kilometres of Canada's boreal forest will

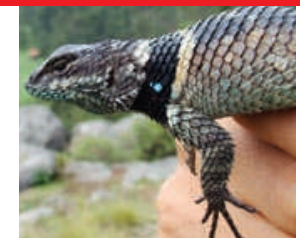

LIZARDS' DARK FUTURE

Climate change could make one-fifth of species extinct by 2080 .

go.nature.com/ag4nBn

\section{选}

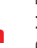

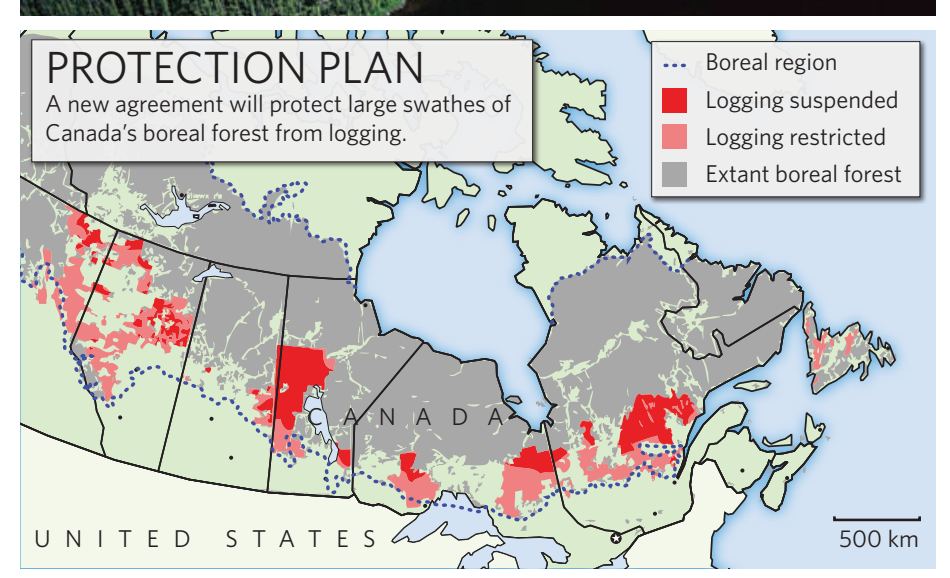

be off-limits to logging, which will make it the largest area of protected forest in the world. This is good news for caribou, whose numbers in Canada have been in steep decline. But it may also slow down global warming, given mounting evidence that boreal forests are important carbon stores.

"Protecting these forests and their soil, which has enormous amounts of carbon, is a hugely important step forward," says Stuart Pimm, a conservation ecologist at Duke University in Durham, North Carolina, who advises Pew.

Unlike tropical forests, which constantly recycle atmospheric carbon through phases of growth and decay, boreal forests experience less decay and instead tend to pool carbon in soil and peat. A recent study led by Sebastiaan Luyssaert, a biologist at the University of Antwerp, Belgium, found that mature boreal forests remain active carbon sinks rather than becoming carbon-neutral ecosystems as they mature (S. Luyssaert et al. Nature 455, 213-215; 2008). "As long as they're alive, they keep accumulating carbon," says Luyssaert.

The northern circumpolar permafrost region, which includes most of the boreal forests earmarked for protection, contains "approximately $50 \%$ of the estimated global belowground organic carbon pool", according to a study co-authored by Josep Canadell, director of the Global Carbon Project in Canberra, Australia (C. Tarnocai et al. Global Biogeochem. Cy. 23, GB2023; 2009). Canadell says that cutting down forests sometimes results in the drying out of wetlands and peat bogs and the release of their huge carbon stores - which hold an average of 7,800 tonnes of carbon per hectare, far more than any other ecosystem.

But Werner Kurz, a senior researcher at the Canadian Forest Service in Victoria, British Columbia, isn't sure that forest conservation is going to slow down warming. Given the speed of climate change, it's not clear that intact forests will necessarily be more resilient than well-managed ones, he says. For instance, harvesting old-growth trees and replacing them with seeds obtained from warmer climes can produce trees that will better withstand temperature increases, he says, and as such would be more likely to thrive and sequester carbon.

"We're still not sure exactly how useful these forests are going to be in mitigating global warming," says Hank Margolis, a forest ecosystem scientist at Laval University in Quebec City, who heads the Canadian Carbon Program. "That's why it makes sense to keep them intact until we figure it out. And to do that, we're going to need to do a lot of science."

The forests may fare better than the research programmes. For years, the Canadian government has declined to renew funding for the Canadian Foundation for Climate and Atmospheric Sciences - its granting agency dedicated to climate research in universities. "I'm afraid most of our research will die out by the end of the year," says Dawn Conway, the foundation's executive director.

Christopher Pala 